\title{
CORRIGENDA
}

\section{Urocortin-1 and -2 double-deficient mice show robust anxiolytic phenotype and modified serotonergic activity in anxiety circuits}

\author{
A Neufeld-Cohen, AK Evans, D Getselter, A Spyroglou, A Hill, S Gil, M Tsoory, F Beuschlein, CA Lowry, \\ $W$ Vale and $A$ Chen
}

Molecular Psychiatry (2010) 15, 442; doi:10.1038/mp.2009.135

Correction to: Molecular Psychiatry (2010) 15, 426-441

(this issue); doi: 10.1038/mp.2009.115

After the online publication of this article, the authors noted that some funding information had been omitted. The complete acknowledgements section should have appeared as follows:

We thank Dr C Kenyon and Dr E Aldujaili (Endocrinology Unit, Centre for Cardiovascular Science, the Queen's Medical Research Institute, Edinburgh, UK) for providing the specific corticosterone antibody and for guiding us through the enzyme-linked immunosorbent assay protocol they developed. AC is the incumbent of the Philip Harris and Gerald Ronson Career Development Chair. WV is a Clayton Medical Research Foundation Senior Investigator and the Helen McLoraine Professor of Molecular Neurobiology. This work is supported by a research grant from the German Israeli Foundation for Scientific Research and Development, a research grant from the Israel Science Foundation, a research grant from the Institute for the Study of Affective Neuroscience, a research grant from the Israel Ministry of Health, a research grant from Roberto and Renata Ruhman, a grant from Mr and Mrs Mike Kahn, a research grant from Mr Jorge David Ashkenazi, a research grant from Mr and Mrs Barry Wolfe, a research grant from the Irving B Harris Foundation, a research grant from Green Irwin Alzheimer's Research, a research grant from the Joseph D Shane Fund for Neuroscience, a grant from the Estate of Ernst and Anni Deutsch (RPH Promotor Stiftung), a grant from the Hana and Julius Rosen Fund, a grant from the Mel and Joyce Eisenberg Keefer Professional Chair for New Scientists, a research grant from $\mathrm{Mr}$ and Mrs Gerhard and Hannah Bacharach, a research grant from the Nella and Leon Benoziyo Center for Neurosciences, a grant from Fondation Fernande et Jean Gaj, a research grant from the Woman's Health Research Center, a research grant from the Abisch-Frenkel Foundation for the Promotion of Life Sciences, and a research grant from the Carl and Micaela Einhorn-Dominic Institute for Brain Research. CAL is supported by a NARSAD 2007 Young Investigator Award. This work is supported by award DK026741-30 from the National Institute of Diabetes and Digestive and Kidney Diseases. The content is solely the responsibility of the authors and does not necessarily represent the official views of the National Institute of Diabetes and Digestive and Kidney Diseases or the National Institutes of Health.

\section{Analysis of gene expression in two large schizophrenia cohorts identifies multiple changes associated with nerve terminal function}

PR Maycox, F Kelly, A Taylor, S Bates, J Reid, R Logendra, MR Barnes, C Larminie, N Jones, M Lennon, C Davies, JJ Hagan, CA Scorer, C Angelinetta, T Akbar, S Hirsch, AM Mortimer, TRE Barnes and $\mathrm{J}$ de Belleroche

Molecular Psychiatry (2010) 15, 442-443; doi:10.1038/mp.2009.148

Correction to: Molecular Psychiatry (2009) 14: 1083-1094; advance online publication, March 3, 2009; doi:10.1038/mp.2009.18
After appearing online, a mistake was noted in the author list of reference 48. Reference 48 appeared as: 
Basu S, Pathak SK, Chatterjee G, Pathak S, Basu J, Kundu M. The neurotransmitter dopamine inhibits angiogenesis induced by vascular permeability factor/ vascular endothelial growth factor. Nat Med 2001; 7: $569-574$.
The correct version is as follows:

Basu S, Nagy JA, Pal S, Vasile E, Eckelhoefer IA, Bliss VS, et al. The neurotransmitter dopamine inhibits angiogenesis induced by vascular permeability factor/vascular endothelial growth factor. Nat Med 2001; 7: 569-574.

\section{BNDF modulates normal human hippocampal ageing}

F Sambataro, VP Murty, HS Lemaitre, JD Reed, S Das, TE Goldberg, JH Callicott, DR Weinberger and VS Mattay

Molecular Psychiatry (2010) 15, 443; doi:10.1038/mp.2010.16

Correction to: Mol Psychiatry (2010) 15: 116-118; doi:10.1038/mp.2009.64

After the publication of this article, the authors noticed that the article title and title of the supplementary files were incorrect. The correct title is:

BDNF modulates normal human hippocampal ageing 